\title{
Effect of interactions between granulosa and thecal cells on meiotic arrest in bovine oocytes
}

\author{
F. Kotsuji, M. Kubo and T. Tominaga \\ Department of Obstetrics and Gynecology, Fukui Medical School Matsuoka-Cho, Yoshida-Gun, \\ Fukui-Ken 910-11, Japan
}

\begin{abstract}
An in vitro culture system in which two types of cell from ovarian follicular walls were attached to opposite surfaces of a collagen membrane was developed. The effect of granulosa-theca cell communication on oocyte maturation was investigated using this culture system. Bovine cumulus-oocyte complexes were incubated with granulosa cells, with or without theca cells. The time course of germinal vesicle breakdown was assessed. When cultured with granulosa cells alone, oocytes showed 100\% germinal vesicle breakdown after incubation for $6 \mathrm{~h}$. However, when cultured with granulosa and theca cells, germinal vesicle breakdown was significantly delayed for up to $12 \mathrm{~h}$. Breakdown was further delayed by $12 \mathrm{~h}$ when cumulus-oocyte complexes were incubated with FSH-treated granulosa and thecal cultures. FSH did not exert this inhibitory effect when in culture with granulosa cells alone. When cumulus-oocyte complexes were incubated with thecal cells alone, all oocytes underwent germinal vesicle breakdown within $6 \mathrm{~h}$; the addition of FSH to the culture medium did not affect the time course of breakdown. It is concluded that a signal(s) from thecal cells augments the meiosis-arresting activity of granulosa cells and that FSH increases the meiosis-arresting activity of granulosa cells under the influence of thecal cells.
\end{abstract}

\section{Introduction}

Fully grown oocytes of all mammalian species are meiotically arrested by a follicular inhibitor until the preovulatory surge of LH. Although the nature of this inhibitor has not been definitely established, it is believed to originate in the membrana granulosa. The association between the germ cell and granulosa cells is believed to be crucial for maintaining oocyte meiotic arrest (Buccione et al., 1990). However, the mechanism involved in the control of meiotic arrest by granulosa cells is poorly understood.

Studies by Kotsuji et al. (1990) indicated that the interaction between granulosa and thecal cells is an important component of the mechanism controlling the function of follicular cells. We developed an in vitro culture system in which two types of cell of the ovarian follicular wall, granulosa and thecal cells, were attached to opposite surfaces of a collagen membrane. The advantages of this in vitro model are: (1) it more closely resembles the in vivo environment, in which both types of cell are separated by an extracellular matrix and (2) changes in granulosa and thecal cells can be observed simultaneously. This culture system has allowed us to investigate the effects of interactions between granulosa and thecal cells on cellular morphology, structure and steroidogenesis. These two types of follicular cell have been shown to reciprocally modulate their proliferation, morphology and steroidogenic function (Kotsuji et al., 1990).

Received 23 March 1993
The present study examined how the meiosis-arresting activity of bovine granulosa cells is modulated by the presence of bovine thecal cells. The effect of FSH treatment on the meiosis-arresting activity of granulosa cells was also investigated because this is the primary gonadotrophin affecting antral follicular granulosa cells and bovine follicular fluid contains FSH or FSH-like substances (Henderson et al., 1982; Dieleman et al., 1983).

\section{Materials and Methods}

Preparation of granulosa and thecal cells

Ovaries were obtained from an abattoir. Granulosa and thecal cells were prepared according to the method described by Kotsuji et al. (1990). Briefly, granulosa cells were collected from small (3-4 $\mathrm{mm}$ ) bovine ovarian follicles by aseptic needle aspiration and were suspended in a culture medium consisting of Waymouth's MB 751/1 medium (Gibco, Grand Island, NY), Hanks' solution (Gibco) and fetal calf serum (6:3:2 v:v:v); $100 \mathrm{U}$ penicillin $\mathrm{ml}^{-1}$ and $100 \mu \mathrm{g}$ streptomycin $\mathrm{ml}^{-1}$ (Sigma Chemical Co., St Louis, MO) were also added. The theca interna layer was removed from follicles of $6-10 \mathrm{~mm}$ in diameter. Granulosa cells, together with a part of the thecal cell layer, were removed from the theca interna by scraping with a knife. The thecal cell layer obtained was minced and then treated with $0.4 \%$ collagenase (Type 1, Sigma) and $0.03 \%$ DNAase (Sigma) in Hanks'-Hepes buffer containing 0.4\% BSA 


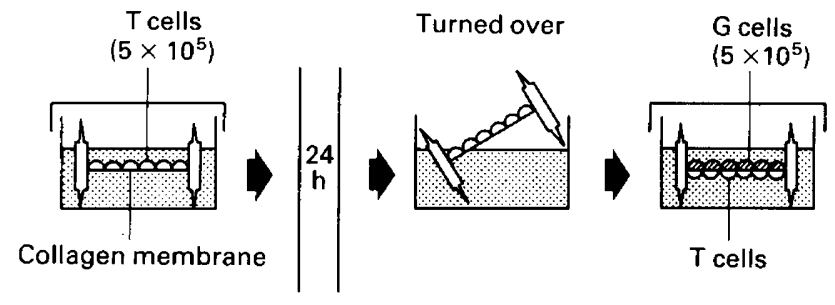

Fig. 1. Culture of thecal and granulosa cells from bovine ovaries. The membrane was made of Type-I collagen and has an area of $8 \mathrm{~cm}^{2}$. Apical and basal chambers were separated by the membrane. Viable thecal $(\mathrm{T})$ cells $\left(5 \times 10^{5}\right)$ were plated onto collagen membranes and cultured until day 5 . On the second day of culture, each membrane was turned over, and freshly prepared viable granulosa $(G)$ cells $\left(5 \times 10^{5}\right)$ were placed onto the opposite surface and cultured until day 5 . As a control, granulosa cells were cultured alone on one side of a collagen membrane on day 2 .

and $0.2 \%$ glucose ( $\mathrm{pH} 7.4$ ). Digestion was continued for $30-60 \mathrm{~min}$ at $37^{\circ} \mathrm{C}$ with continuous stirring at 80 r.p.m. The thecal cells were then further digested for $8 \mathrm{~min}$ with $0.25 \%$ pancreatin (Sigma) in Hanks'-Hepes buffer. Dispersed cells were washed with culture medium, and cell viability was assessed by trypan blue dye exclusion (93-96\%).

\section{Culture of granulosa and thecal cells on collagen membranes}

Viable thecal cells $\left(5 \times 10^{5}\right)$ were plated onto collagen membranes (Koken Co, Ltd, Tokyo) in $5 \mathrm{~cm}$ plastic dishes (Fig. 1). On day 2 of culture, each membrane was turned over, and freshly prepared viable granulosa cells $\left(5 \times 10^{5}\right)$ were placed onto the opposite surface. The culture was then continued until day 5. As a result, thecal cells were cultured for 4 days and granulosa cells for 3 days. As a control, granulosa cells were cultured, alone, on one side of a collagen membrane. Cells were cultured at $39^{\circ} \mathrm{C}$ in a humidified atmosphere of $5 \% \mathrm{CO}_{2}$ and $95 \%$ air, with the medium maintained at $\mathrm{pH} 7.4$.

\section{Culture of cumulus-oocyte complexes and observation of germinal vesicle breakdown}

Cumulus-oocyte complexes were collected from bovine ovaries without preovulatory follicles or corpora lutea. Small (3-6 mm diameter) follicles on the surface of the ovaries were randomly incised and the ovaries rinsed in a plastic dish containing fresh follicular fluid that had been prepared in advance. The cumulus-oocyte complexes obtained from several ovaries were collected under a stereomicroscope. All procedures were performed on a warm stage $\left(39^{\circ} \mathrm{C}\right)$. Complexes were used for the following studies within $5 \mathrm{~min}$ of removal from the follicles. The oocytes were incubated at $39^{\circ} \mathrm{C}$ in a humidified atmosphere of $5 \% \mathrm{CO}_{2}: 95 \%$ air in all the experiments. Only oocytes with tightly attached cumulus cells were used for the study.

At the end of culture, cumulus-oocyte complexes were transferred into $0.2 \%$ hyaluronidase (Sigma) in saline. The cumulus cells surrounding the oocytes were removed using a glass pipette. Oocytes were then fixed onto glass slides and treated with a mixture of acetic acid and ethanol $(1: 3, \mathrm{v}: \mathrm{v})$ for
$72 \mathrm{~h}$. Oocytes were stained with $1 \%$ orcein in $45 \%$ acetic acid, and then rinsed with a mixture of $20 \%$ glycerol and $20 \%$ acetic acid. The presence of germinal vesicles was assessed by light microscopy and, if germinal vesicles were detected, the oocyte was classified as showing meiotic arrest. Resumption of meiosis was indicated by the absence of a germinal vesicle.

\section{Effects of interaction between granulosa and thecal cells on the meiosis-arresting activity of granulosa cells}

In Expt 1, the time course of germinal vesicle breakdown in oocytes cultured with granulosa cells, alone or together with thecal cells, was assessed. Five collagen membranes with granulosa and thecal cells, and five membranes with granulosa cells alone were prepared. On the morning of day 5 of culture, each collagen membrane was washed with fresh medium and then transferred into a plastic dish containing fresh culture medium. Eighteen to twenty cumulus-oocyte complexes were placed on the granulosa cell side of each membrane. As controls, complexes were cultured in plastic dishes containing freshly prepared culture medium. After incubation for 3, 6, 9, 12 and $24 \mathrm{~h}$, the cumulus-oocyte complexes from a single culture were assessed for the presence of a germinal vesicle.

\section{Effects of FSH treatment on the meiosis-arresting activity of granulosa cells}

In Expt 2, the effects of FSH treatment of granulosa cells on germinal vesicle breakdown were examined. Ten collagen membranes with both granulosa and theca cells, and ten membranes with granulosa cells alone were prepared. Five cultures from each group were cultured with medium containing FSH (NIADDK-ovine FSH-17, $500 \mathrm{ng} \mathrm{ml}^{-1}$ ) from day 2 to day 5. Less than $1 \%$ FSH had passed to the opposite side of the culture chamber after $72 \mathrm{~h}$ when added to the medium on one side of the membrane. On the morning of day 5 , each collagen membrane was washed with fresh medium and then transferred into a plastic dish containing fresh culture medium without FSH. Eighteen to twenty cumulus-oocyte complexes were placed on the granulosa cell side of each membrane, and the time course of germinal vesicle breakdown was determined.

Time course of germinal vesicle breakdown in oocytes cultured in conditioned medium and oocytes cultured directly on granulosa cells

In Expt 3, the time course of germinal vesicle breakdown in oocytes cultured in conditioned medium was compared with that of oocytes cultured directly on granulosa cells. Five collagen membranes with both granulosa and thecal cells were prepared and the granulosa cells of each membrane were treated with FSH (NIADDK-ovine FSH- $17.5 \mu \mathrm{g} \mathrm{ml}^{-1}$ ) from day 2 to day 5 . On the morning of day 5 of culture, conditioned medium obtained from the granulosa cell side of each membrane was transferred into plastic dishes $3 \mathrm{~cm}$ in diameter. Each collagen membrane was washed with fresh medium and then transferred into a plastic dish containing fresh culture medium. Cumulus-oocyte complexes were incubated in the conditioned medium or on granulosa cells of each 

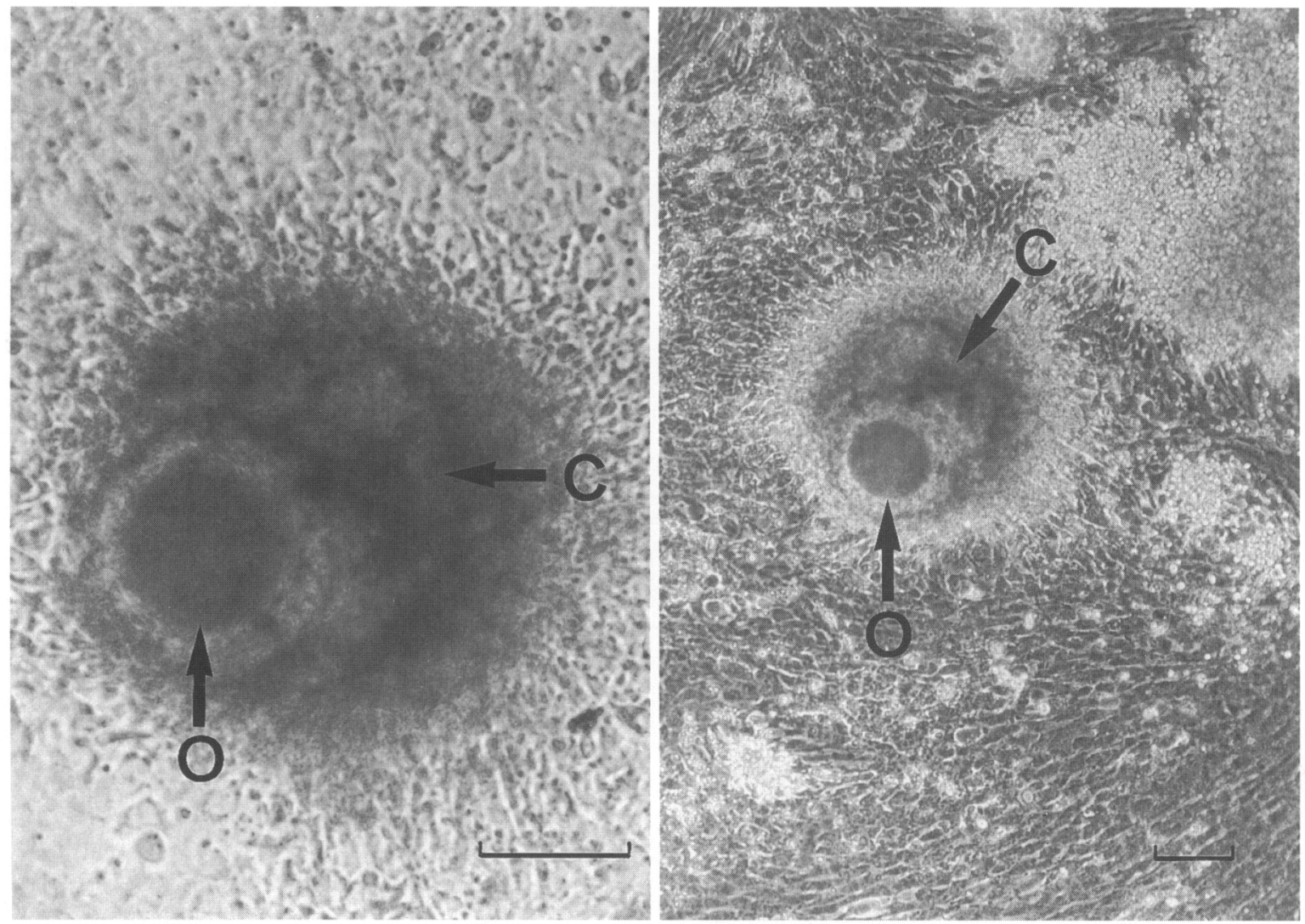

Fig. 2. Bovine cumulus-oocyte complexes incubated on granulosa cells with thecal cells for $9 \mathrm{~h}$. Tight attachment between granulosa and cumulus cells was observed after $30 \mathrm{~min}$ of incubation. O: oocyte; C: cumulus cells. Scale bars represent $100 \mu \mathrm{m}$.

membrane. As controls, complexes were cultured in plastic dishes containing freshly prepared culture medium containing FSH.

\section{Culture of oocytes directly on thecal cells}

In Expt 4, germinal vesicle breakdown in oocytes cultured directly on thecal cells was investigated. Ten membranes with thecal and granulosa cells were prepared. On day 5 of culture, each collagen membrane was washed with fresh medium and then transferred into a plastic dish containing fresh culture medium. Each membrane was turned over and thecal cells were placed on the apical surface of the membrane. FSH $\left(500 \mathrm{ng} \mathrm{ml}^{-1}\right.$ ) was added to the culture medium on the thecal cell side of five cultures, and then 18-20 cumulusoocyte complexes were cultured on the thecal cells attached to the collagen membranes. As control, complexes were cultured in plastic dishes containing freshly prepared culture medium.

\section{Statistical analysis}

Each experiment was repeated four times and the results of the four experiments were combined. Data are presented as means \pm SEM of four different experiments. For comparing the percentage of oocytes containing germinal vesicles, either Duncan's new multiple range test or Student's $t$ test was used. A $P$ value less than 0.05 was considered statistically significant.

\section{Results}

Germinal vesicle breakdown in oocytes cultured with granulosa cells alone or with thecal cells

Cumulus-oocyte complexes incubated on granulosa cells with thecal cells for $9 \mathrm{~h}$ are shown (Fig. 2). Tight attachment between the granulosa and cumulus cells was observed after $30 \mathrm{~min}$ of incubation in the presence or absence of thecal cells and was confirmed by gentle agitation.

When cumulus-oocyte complexes were incubated in fresh culture medium, $100 \%$ of the oocytes underwent germinal vesicle breakdown within $6 \mathrm{~h}$ (Fig. 3). When complexes were incubated with granulosa cells alone, breakdown occurred in $100 \%$ of the oocytes after $9 \mathrm{~h}$. The percentage of oocytes containing germinal vesicles was significantly higher than that at $3 \mathrm{~h}$, but not that at $6 \mathrm{~h}$, for cumulus-oocyte complexes cultured in fresh medium.

When complexes were incubated with granulosa cells together with thecal cells, $100 \%$ germinal vesicle breakdown did not occur until $24 \mathrm{~h}$ in culture. The percentage of oocytes containing germinal vesicles after $3,6,9$ and $12 \mathrm{~h}$ in culture was significantly higher than when cumulus-oocyte complexes were cultured with granulosa cells alone. 


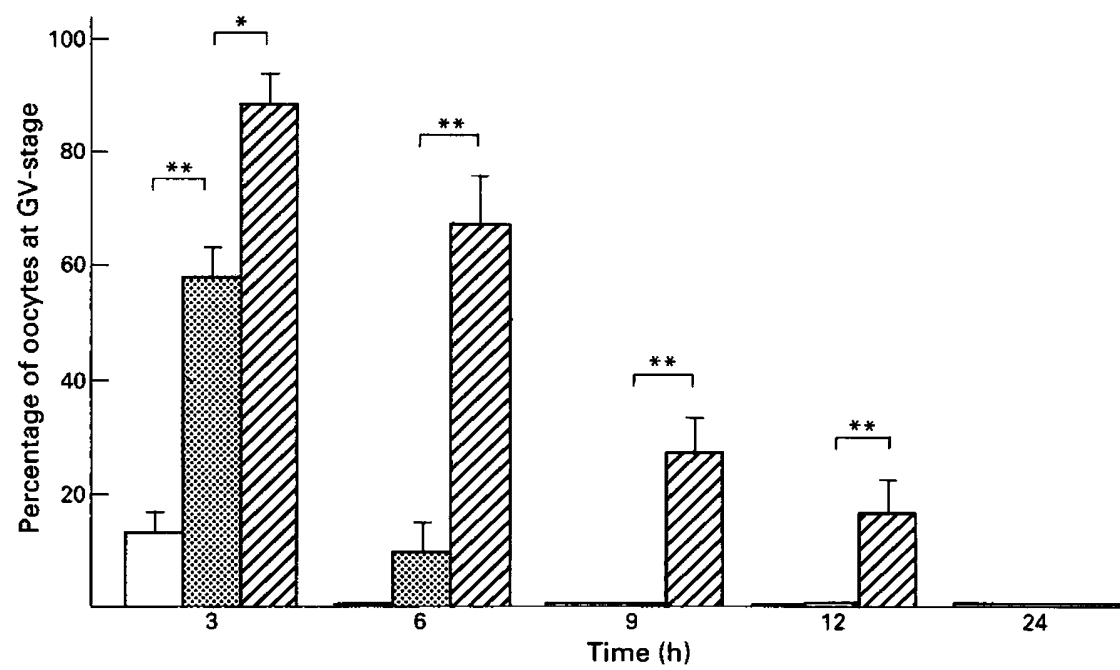

Fig. 3. Percentage of bovine oocytes at germinal vesicle stage (GV) when cumulus-oocyte complexes were incubated in ( $\square$ ) fresh culture medium, (國) with granulosa cells alone and ( $\triangle$ ) with granulosa cells together with theca cells for $3,6,9,12$ and $24 \mathrm{~h}$. Significantly different $\left({ }^{*} P<0.05\right.$ and $\left.{ }^{* *} P<0.01\right)$.

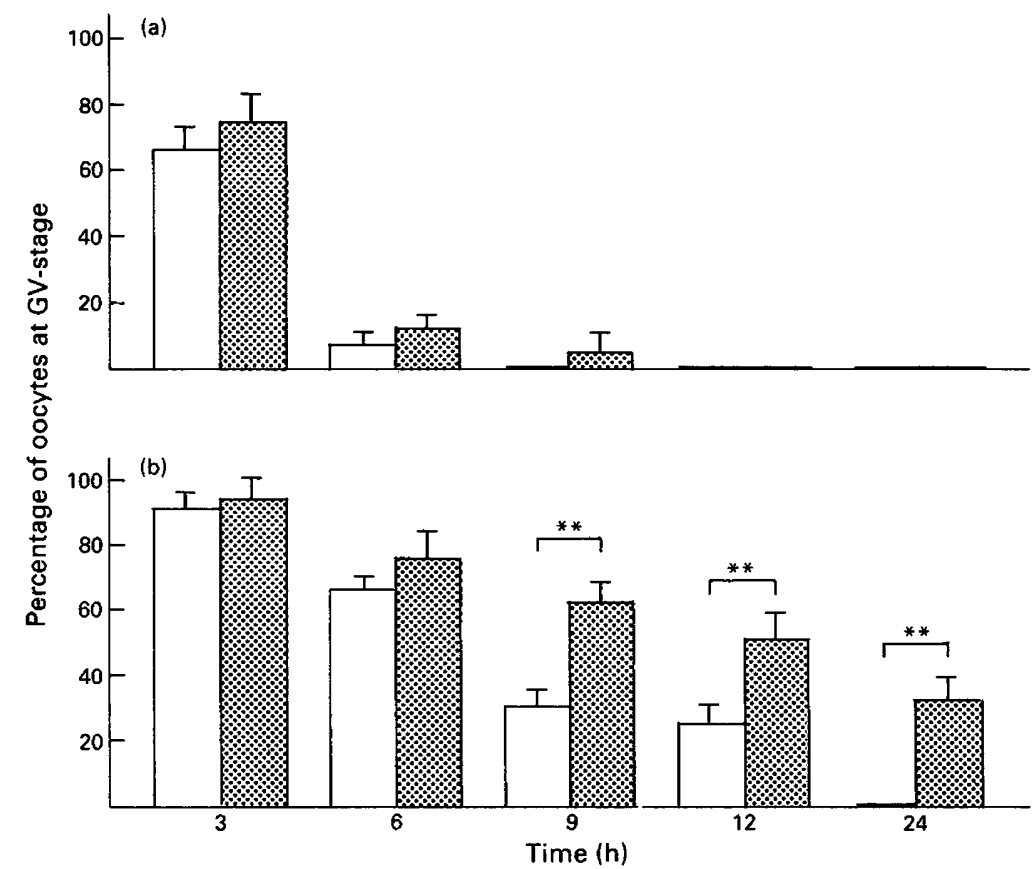

Fig. 4. Effects of FSH treatment of bovine granulosa cells on meiosis-arresting activity of granulosa cells. (a) Results when cumulus-oocyte complexes were incubated on granulosa cells cultured alone. (b) Results when complexes were incubated on granulosa cells cultured together with thecal cells. Granulosa cells were cultured $(\square)$ with or (圆) without FSH. Significantly different $\left({ }^{* *} P<0.01\right)$. GV: germinal vesicle.

Effect of FSH treatment of granulosa cells on meiosis-arresting activity

When cumulus-oocyte complexes were cultured with FSHtreated granulosa cells alone, $100 \%$ germinal vesicle breakdown was detected after $12 \mathrm{~h}$ of incubation. However, the percentage of oocytes containing germinal vesicles at 3,6 and $9 \mathrm{~h}$ of incubation was not significantly different from that of oocytes incubated with granulosa cells that had not been treated with FSH (Fig. 4a). In contrast, FSH induced delay of germinal vesicle breakdown when complexes were cultured with granulosa cells together with thecal cells (Fig. 4b). After $24 \mathrm{~h}$ incubation, $33 \pm 6 \%$ of oocytes still remained at the germinal vesicle stage. The percentage of oocytes at the germinal vesicle 


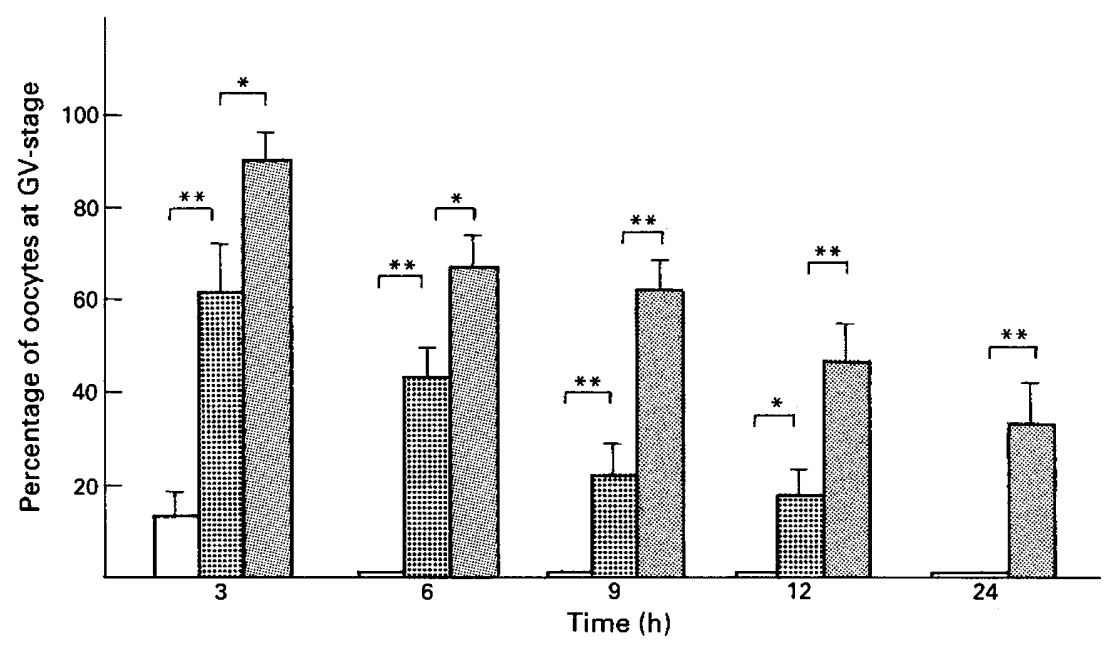

Fig. 5. Percentage of bovine oocytes at germinal vesicle stage when cumulus-oocyte complexes were incubated in conditioned medium or on granulosa cells. Results when complexes were incubated $(\square)$ in fresh culture medium with FSH, (圆) in conditioned medium and (圆) on granulosa cells. Significantly different $\left({ }^{*} P<0.05\right.$ and $\left.{ }^{* *} P<0.01\right)$.

stage at 9 and $12 \mathrm{~h}$ of culture was significantly higher than when oocytes were incubated with untreated granulosa cells together with thecal cells.

\section{Germinal vesicle breakdown in oocytes cultured in conditioned medium}

When cumulus-oocyte complexes were incubated in conditioned medium, obtained from the granulosa cell side of granulosa-thecal cell cocultures after $72 \mathrm{~h}$ culture, germinal vesicle breakdown was delayed when compared with complexes incubated in fresh culture medium. However, the percentage of oocytes with germinal vesicles after incubation for $3,6,9,12$ and $24 \mathrm{~h}$ was significantly lower than when cumulus-oocyte complexes were cultured directly on granulosa cells (Fig. 5).

\section{Germinal vesicle breakdown in oocytes cultured with thecal cells}

When cumulus-oocyte complexes were cultured with thecal cells only, germinal vesicle breakdown occurred in $100 \%$ of the oocytes after $6 \mathrm{~h}$ of incubation in the presence and absence of FSH. The percentage of oocytes with germinal vesicles after incubation for $3 \mathrm{~h}(14.6 \pm 4.1$ in the presence of FSH and $10.1 \pm 2.6$ in the absence of $\mathrm{FSH}$, respectively) was not significantly different from that for oocytes incubated in fresh medium $(13.5 \pm 3.0 \%)$.

\section{Discussion}

The occurrence of germinal vesicle breakdown in oocytes incubated with granulosa cells cultured alone was delayed when compared with that for oocytes incubated in fresh culture medium. This finding supports the study of Tsafriri and Channing (1975) who reported that granulosa cells possess meiosis-arresting activity. Further delay of germinal vesicle breakdown was observed when complexes were incubated with granulosa-thecal cell cocultures. We conclude that thecagranulosa cell interaction may play an important role in the meiosis-arresting activity of granulosa cells.

Under the present experimental conditions, germinal vesicle breakdown was further delayed when cumulus-oocyte complexes were incubated with granulosa-thecal cell cocultures pretreated with $\mathrm{FSH}$. There are two possible explanations for this further delay. First, it is possible that FSH together with signal(s) originating from the thecal cells directly affects the oocyte or cumulus cells inhibiting meiotic maturation. The second possibility is that FSH and a signal(s) originating from the thecal cells augment the meiosis-arresting activity of granulosa cells. Schultz et al. (1983) and Eppig et al. (1983) reported that FSH has meiosis-arresting activity on mouse oocytes, although its effect is transient $(<4 \mathrm{~h})$. In the present study, however, no significant delay of breakdown was detected when cumulus-oocyte complexes were incubated with thecal cells alone, in the presence or absence of FSH, when compared with oocytes cultured in fresh medium. Our results, therefore, do not support the first possibility. Thus we conclude that FSH probably augments the meiosis-arresting activity of granulosa cells under the direct control of thecal cells.

The mechanism by which thecal cells modulate the meiosisarresting activity of granulosa cells is of interest. It is known that granulosa cells cultured alone in vitro undergo luteinization (Gier and Marion, 1961; Henderson and Moon, 1979; Skinner and Osteen, 1988). In a previous study (Kotsuji et al., 1990), the morphology, proliferation and steroidogenesis of granulosa cells cocultured with thecal cells were compared with those of granulosa cells cultured alone. Granulosa cells cultured alone were flattened and formed a monolayer, whereas granulosa cells, cultured with thecal cells, became convex and formed multi-layers. Proliferation of these cells increased twofold but their ability to secrete progesterone was reduced to one-third of that of cells cultured alone. These observations suggest that luteinization of granulosa cells is reduced in the presence of 


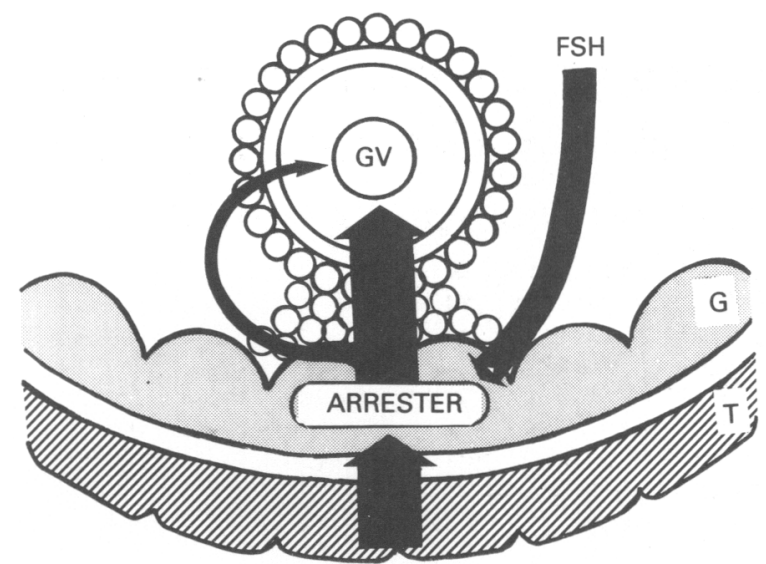

Fig. 6. Hypothetical role of interaction between granulosa $(G)$ and thecal $(T)$ cell on meiotic arrest of the oocyte. GV: germinal vesicle.

thecal cells. One possible explanation for the observations in this study is that interactions between thecal and granulosa cells inhibited the luteinization of granulosa cells, resulting in maintenance of the meiosis-arresting activity of granulosa cells. It therefore seems that granulosa cells cocultured with thecal cells more closely resemble the morphology and function of follicular cells in vivo than when these cells were cultured alone. We propose that the interaction between these two types of follicular cells is essential for the maintenance of the original structure and function of bovine follicular cells.

Previous studies have suggested that there are two possible physiological means through which the granulosa cell meiotic arrester could be transmitted to the oocyte. First, the arrester may be transmitted to the oocyte by transfer through the numerous gap junctions known to connect the membrana granulosa cells, the cumulus cells, and the innermost layer of cumulus granulosa cells with the oolemma (Tsafriri and Channing, 1975; Leibfried et al., 1980; Eppig, 1991). The second possible way that the arrester could be transmitted to the oocyte is by secretion into the extracellular follicular fluid, from which it would be taken up either directly into the oocyte or indirectly via the adherent cumulus cells (Gwatkin et al., 1976; Hillensjo et al., 1979). In the present study, conditioned medium, obtained after culture for $72 \mathrm{~h}$ from the granulosa cell side of granulosa-theca cocultures, showed meiosis-arresting activity. However, germinal vesicle breakdown was further delayed when cumulusoocyte complexes were cultured directly on granulosa cells, suggesting that the meiosis arrester is mainly transported to the oocyte across the junctions between granulosa cells and cumulus cells in our culture system. Alternatively, the arrester secreted into culture medium could be unstable. Racowsky and Baldwin (1989) reported that meiotic arrest in hamster oocytes is maintained only transiently by follicular fluid, but is maintained persistently by contact between membrana and cumulus granulosa cells. Larsen and Risinger (1985) and Racowsky et al. (1989) reported that gap junctions can assemble within minutes in tissue cultures and that such junctions can provide a physical pathway for intercellular communication. The meiosis arrester is therefore probably transported across the junctions between granulosa cells and cumulus cells (Fig. 6) and is also secreted into the culture medium and taken up either directly through the oocyte or indirectly via the adherent cumulus cells.

In conclusion, interaction between thecal and granulosa cells may play an important role in the meiosis-arresting activity of granulosa cells. FSH augments the meiosis-arresting activity of granulosa cells under the control of thecal cells. The meiosis arrester from granulosa cells is probably transported mainly via intercellular junctions with cumulus cells.

The authors would like to thank the management of Kanazawa Meat Inspection Office (Kanazawa, Japan) for allowing us to collect the bovine ovaries used in these experiments. They also wish to thank Y. Hosoi (Department of Agriculture, University of Kyoto, Kyoto, Japan) for his technical advice as well as M. Misawa and M. Taniguchi for their technical assistance.

\section{References}

Buccione R, Schroeder AC and Eppig JJ (1990) Interactions between somatic cells and germ cells throughout mammalian oogenesis Biology of Reproduction $\mathbf{4 3}$ 543-547

Dieleman SJ, Bevers MM, Poortman J and Van Tol HTM (1983) Steroid and pituitary hormone concentrations in the fluid of preovulatory bovine follicles relative to the peak of $\mathrm{LH}$ in the peripheral blood Joumal of Reproduction and Fertility 69, 641-649

Eppig JJ (1991) Intercommunication between mammalian oocytes and com panion somatic cells Bioessays 13 569-574

Eppig JJ, Freter RR, Ward-Bailey PF and Schultz RM (1983) Inhibition of oocyte maturation in the mouse: participation of cAMP, steroids, and a putative maturation inhibitory factor Developmental Biology $10039-49$

Gier HT and Marion GB (1961) Formation of the bovine corpus luteum Journal of Dairy Science 44 1187-1192

Gwatkin RBL and Anderson OF (1976) Hamster oocyte maturation in vitro: inhibition by follicular components Life Sciences $19527-536$

Henderson AJ and Moon YS (1979) Hormonal regulation of the differentiation of cultured ovarian granulosa cells Journal of Reproduction and Fertility 56 89-97

Henderson KM, McNeilly AS and Swanston IA (1982) Gonadotrophin and steroid concentrations in bovine foilicular fluid and their relationship to follicle size Journal of Reproduction and Fertility 65 467-478

Hillensjo T, Channing CP, Pomerants SH and Sahwartz-Kripner A (1979) Intrafollicular control of oocyte maturation in the pig In Vitro 15 32-39

Kotsuji F, Kamitani N, Goto K and Tominaga T (1990) Bovine theca and granulosa cell interactions modulate their growth, morphology and function Biology of Reproduction $\mathbf{4 3} 726-732$

Larsen WJ and Risinger MA (1985) The dynamic life histories of intercellular membrane junctions Molecular and Cellular Biology 4 151-216

Leibfried L and First NL (1980) Follicular control of meiosis in the porcine oocyte Biology of Reproduction 23 705-709

Racowsky C and Baldwin KV (1989) In vitro and in vivo studies reveal that hamster oocyte meiotic arrest is maintained only transiently by follicular fluid, but persistently by membrana/cumulus granulosa cell contact Developmental Biology 134 297-306

Schultz RM, Montgomery R and Belanoff J (1983) Regulation of mouse oocyte meiotic maturation; implication of a decrease in oocyte cAMP and protein dephosphorylation in commitment to resume meiosis Developmental Biology $97264-278$

Skinner MK and Osteen KG (1988) Developmental and hormonal regulation of bovine granulosa cell function in the preovulatory follicle Endocrinology $\mathbf{1 2 3}$ 1668-1675

Tsafriri A and Channing CP (1975) An inhibitory influence of membrana granulosa cells and follicular fluid upon porcine oocyte meiosis in vitro Endocrinology 96 922-927 